\title{
Cuidador familiar do idoso com transtorno mental e comportamental: vivências e sentimentos desvelados
}

\author{
Family caregivers of older adults with mental and behavioral disorders: experiences and \\ feelings unveiled
}

\author{
Los cuidadores familiares de ancianos con trastorno mental y comportamental: \\ experiencias y sentimientos revelados
}

\author{
Milara Barp'; Sueli de Carvalho VilelaII
}

\begin{abstract}
RESUMO: O objetivo foi compreender a experiência do cuidador informal quanto ao cuidar de idoso com transtorno mental comportamental. Trata-se de estudo qualitativo, descritivo de caráter fenomenológico-existencial, realizado por meio de entrevistas abertas com 12 cuidadoras de idosos portadores de transtorno mental ou comportamental, em cidade de Minas Gerais, em 2014. Utilizou-se o referencial teórico de Heidegger e o Método Fenomenológico de Giorgi para análise dos conteúdos manifestos. Os resultados evidenciaram quatro estruturas de experiência: Vivenciando a facticidade em seu mundo-vida; Ser-cuidadore o abandono de si mesmo e dos outros entes; Ser-cuidador lançado no mundo do ser idoso; Ser-com encontra na fé um novo sentido para o cuidado. Estas estruturas representam a essência da vivência dos sujeitos cuidadores de idosos com desordens psiquiátricas. O conhecimento aqui desvelado fornece subsídios para a formulação de estratégias e intervenções para essa população.

Palavras-chave: Enfermagem; cuidadores; família; geriatria.
\end{abstract}

\begin{abstract}
The aim was to understand the experience of informal caregivers of elderly people with behavioral mental disorders. This qualitative, descriptive, existential-phenomenological study was conducted in 2014 through open interviews of twelve caregivers of elderly people with mental or behavioral disorders. The content expressed was analyzed using Heidegger as the theoretical framework and the phenomenological method of Giorgi. The results indicated four units of experience: Experiencing facticity in their life-world; Being-a-caregiver and neglect of self and others; Being-a-caregiverthrown into the world of older adults; and Beingwith finds a new direction for care in faith: these represent the essence of caregivers' experience of elderly subjects with psychiatric disorders. The knowledge unveiled here provides input to the formulation of strategies and interventions for this population. Keywords: Nursing; caregivers; family; geriatrics.

RESUMEN: El objetivo fue comprender la experiencia del cuidador no profesional en cuanto al cuidado de los ancianos con trastorno mental y comportamental. Se trata de un estudio cualitativo, descriptivo, de carácter fenomenológico-existencial, realizado a través de entrevistas abiertas junto a doce cuidadoras de ancianos con trastorno mental o comportamental, en una ciudad de Minas Gerais, en 2014. Se ha utilizado el marco teórico de Heidegger y el Método Fenomenológico de Giorgi para el análisis de los contenidos manifiestos. Los resultados indicaron cuatro estructuras de experiencia: Experimentar la facticidad en su mundo-vida; Ser-cuidadory el abandono de sí mismo y de los otros, Ser-cuidador lanzado al mundo del ser anciano; Ser-con encuentra en la fe un nuevo sentido para la atención. Esas estructuras representan la esencia de la experiencia de los cuidadores de ancianos con trastornos psiquiátricos. El conocimiento presentado aquí proporciona subsidios para la formulación de estrategias e intervenciones hacia esta población. Palabras clave: Enfermería; cuidadores; familia; geriatría.
\end{abstract}

\section{INTRODUÇÃO}

Estimativas apontam que, até 2050, a população com 60 anos ou mais triplicará no Brasil, entretanto o brasileiro que alcançar 75 anos apresentará, em média, 65 anos com qualidade de vida, sendo os últimos 10 associados a doenças e dependência de cuidados ${ }^{1}$.

Com o passar da idade, ocorrem alterações físicas e psicossociais, como o aumento na prevalência de doenças crônico-degenerativas, limitações cognitivas, déficit na capacidade funcional, dependência. Neste período, o idoso vivencia perdas e luto, mudanças de papéis sociais. Todos estes fatores culminam no aumento de doenças mentais comportamentais, pois desencadeiam ou agravam o sofrimento psíquico. Entre as principais doenças psíquicas no idoso destacam-se a ansiedade, demências, transtornos mentais orgânicos, transtornos devido ao uso abusivo de álcool e dependência de medicamentos ${ }^{2,3}$.

A atividade de cuidar do idoso é realizada, predominantemente, por cuidadores informais, ou seja, o

'Graduada em Enfermagem pela Escola de Enfermagem da Universidade Federal de Alfenas. Minas Gerais, Brasil. E-mail: milarabarp@hotmail.com. IIDoutora em Ciências em Enfermagem Psiquiátrica. Professora Adjunta da Escola de Enfermagem da Universidade Federal de Alfenas. Minas Gerais, Brasil. E-mail: suelicvilela@gmail.com. 
elemento da família do idoso ou relacionado que passa a assumir a maior parte das ações do cuidado, sem possuir conhecimento técnico/teórico e sem receber qualquer tipo de remuneração ${ }^{4}$.

$\mathrm{O}$ cuidado ao idoso com transtornos mentais comportamentais é complexo e integral. $O$ cuidador lida com situações que perpassam as necessidades físicas sem qualquer tipo de apoio ou instrumentalização, fazendo com que vivencie um alto nível de sofrimento, desgaste físico e emocional ${ }^{5,6}$.

Considerando a importância do cuidador informal e pela ausência de estudos que enfatizem o sujeito cuidador de idoso com transtornos mentais comportamentais, foi delineada a questão orientadora do estudo: Como é ser cuidador informal do idoso portador de transtorno mental? Supõe-se que, ao entendê-lo, a partir de suas concepções, vivências e significados atribuídos à tarefa de cuidar, é possível compreender sobre as suas reais necessidades, fornecendo subsídios para reflexões nas práticas de profissionais que atendam a essa população.

Diante do exposto, este estudo teve por objetivo compreender a experiência do cuidador informal quanto ao cuidar de idoso com transtorno mental comportamental.

\section{REFERENCIAL TeÓRICO}

Optou-se por utilizar como referencial teórico principal do estudo a analítica existencial do filósofo Martin Heidegger, que, na sua perspectiva, considera que o discurso é uma instância ontológica que permite transmitir vivências, partilhar sentidos e trazer informações do próprio interior do sujeito?

Para o filósofo, o homem estabelece-se sob três perspectivas: a facticidade, a existencialidade e a decadência ${ }^{7}$. A facticidade refere-se ao ser como ser-lançado-no-mundo, ligado à realidade concreta das coisas, a interação de dasein com outro dasein $\square$ o que o torna um ser-com. A existencialidade corresponde à capacidade humana de ver, significar e apropriar-se das coisas do mundo a partir de sua própria perspectiva e a decadência é o fato de o homem abandonar seus próprios interesses em favor de suas ocupações, a ausência de uma vida autêntica ${ }^{8}$.

Heidegger também é considerado o filósofo do cuidado e identifica o processo de cuidar como elemento essencial para a compreensão do mundo e para a existência humana 9 . O cuidado é encontrado em toda atitude e situação de fato, de forma que é um modo-de-ser essencial da humanidade ${ }^{10}$.

No cuidado, o homem, entregue ao mundo da ocupação, precisa deixar de ser o senhor de si, para se transformar no cuidador do ser? ${ }^{7}$. O envolvimento e entrelaçamento inter-humano permite que ele se mostre e manifeste sua angústia de forma autêntica, transcendendo e atingindo um poder-ser-si-próprio ${ }^{10}$.

\section{Metodologia}

Trata-se de estudo qualitativo, descritivo, de caráter fenomenológico-existencial. $\mathrm{O}$ presente estudo foi desenvolvido com 12 cuidadores familiares de idosos portadores de transtorno mental comportamental pertencentes à área de abrangência das unidades de estratégia saúde da família (ESF) de um município de médio porte de Minas Gerais, em 2014.

Os critérios de inclusão dos cuidadores foram: ser cuidador informal do idoso há pelo menos um ano, pertencer à área de abrangência da ESF e possuir capacidade preservada de comunicação e/ou cognitiva. Para os idosos, estes deveriam ser portadores de algum tipo de transtorno mental ou comportamental.

A escolha dos cuidadores ocorreu mediante indicação dos agentes comunitários de saúde (ACS) e enfermeiro das unidades de ESF. Para cada uma das doze unidades de ESF pesquisadas, elaborou-se uma listagem de cuidadores que foram indicados ao se enquadrarem nos critérios de inclusão. Ao final do levantamento, foi sorteado um sujeito de estudo para cada ESF. Optou-se pelo sorteio, considerando que a consciência é considerada sempre intencional, portanto o uso do sorteio buscou evitar a intencionalidade e possíveis vieses de seleção ${ }^{11}$.

Em seguida, contataram-se os sujeitos em seus domicílios, convidando-os a participarem do estudo. Com o aceite, foi agendada a data e o horário para a coleta.

$\mathrm{Na}$ coleta de dados, os cuidadores assinavam o Termo de Consentimento Livre e Esclarecido e os idosos, o termo de assentimento. Em seguida, realizou-se a entrevista aberta, guiada por meio de uma única pergunta: Gostaria que você me contasse o que significa para você cuidar do(a) (nome do idoso)?

As entrevistas foram gravadas em formato digital com duração média de 32 minutos e total de 6 horas e 24 minutos de gravação. Logo após, foram transcritas na íntegra, tornando-se evidências empíricas, as quais foram analisadas de acordo com modelo proposto por Giorgi, composto por quatro etapas: leitura geral do material, definição das unidades de significado, expressão das unidades na perspectiva escolhida pelo pesquisador e formulação de uma síntese das unidades ${ }^{12}$.

Primeiramente, realizaram-se leituras das descrições para se ter um senso geral de tudo o que foi colocado. Tendo o sentido do todo, buscou-se discriminar unidades de significado, que são temas ou essências contidas nas descrições e reveladoras da estrutura do fenômeno. Uma vez delineadas as unidades de significado, novas leituras foram feitas buscando apreender seus conteúdos manifestos. Por último, as unidades de significado foram sintetizadas e transformadas em declarações consistentes com relação à experiência do sujeito - que são as estruturas da experiência ${ }^{13}$. 
$\mathrm{O}$ projeto de pesquisa foi previamente aprovado pelo Comitê de Ética em Pesquisa da Universidade Federal de Alfenas sob o parecer n $n^{\circ} 564.914$ e CAAE número 26776114.0.0000.5142. Para manter o sigilo e anonimato, os nomes dos sujeitos foram codificados com letra maiúscula $\mathrm{C}$ (cuidador), seguida por número ordinal $(\mathrm{C} 1, \mathrm{C} 2 \ldots \mathrm{C} 12)$

\section{Resultados e Discussão}

A amostra foi constituída inteiramente por mulheres cuidadoras, sendo oito filhas $(66,8 \%)$, duas irmãs $(16,6 \%)$ e duas esposas do idoso $(16,6 \%)$, com uma média de idade de 55,41 anos (40-68 anos). Sobre o nível de escolaridade das participantes, seis com ensino fundamental incompleto $(50,07 \%)$, duas com o ensino fundamental completo $(16,6 \%)$, uma com ensino médio incompleto $(8,33 \%)$, três ensino médio completo (25\%). Quanto à renda familiar das cuidadoras, seis apresentavam renda de 1 a 5 salários mensais (50\%), quatro com renda mensal de 5 a 10 salários $(33,3 \%)$ e duas com renda até um salário mensal $(16,7 \%)$.

Quanto ao Transtorno Mental ou Comportamental que o idoso cuidado apresentava, seis idosos possuíam Demência $(50,1 \%)$, outros três Transtorno Depressivo (25\%), um idoso Transtorno Bipolar (8,33\%), um portador de Esquizofrenia (8,33\%) e um idoso dependente de álcool (8,33\%).

A apreciação dos depoimentos possibilitou a elucidação de quatro estruturas de sentido: Vivenciando a facticidade em seu mundo-vida; Ser-cuidador e o abandono de si mesmo e dos outros entes; Ser-cuidador lançado no mundo do ser idoso; Ser-com encontra na fé um novo sentido para o cuidado. Essas estruturas representam a essência da vivência dos sujeitos cuidadores de idosos com desordens psiquiátricas.

\section{Vivenciando a facticidade em seu mundo-vida}

A facticidade existencial está presente no momento em que o homem está à mercê de seu cotidiano, levando-o a agir de acordo com o que dizem ser certo ou errado, obedecendo a ordens e proibições. O ser humano passa a existir no que já é estabelecido, deixando seu modo de ser próprio ${ }^{7}$. No presente estudo, o fatídico é apresentado no momento que o cuidado é considerado um afazer feminino:

[...] É, tem que ser eu, porque sou a única irmã. Eram mais duas, mas já faleceram. Os irmãos... você sabe? Irmão não cuida do outro (C1).

Para essas mulheres, o cuidar passa a ter um significado conforme as expectativas sociais passadas de geração em geração. A naturalidade que assumem o papel de cuidar está relacionada ao papel historicamente feminino de assumir a reponsabilidade pela casa e de cuidar dos filhos, marido, idosos e doentes enquanto o homem assume a responsabilidade pelo sustento familiar ${ }^{14-16}$.

O cuidado realizado pela esposa é também tradicionalmente aceitável, uma vez que a parceira é uma pessoa influente na vida do idoso, aceita esta condição e tampouco é questionada pela família ${ }^{14}$.

Eu me sinto na obrigação de fazer isso. Sendo esposa, eu sou obrigada a fazer. Quer possa ou quer não possa eu sou responsável e tenho que fazer isso (C2).

Entre os fatores que motivam as cuidadoras esposas estão a obrigação e dever moral, compromisso conjugal e a gratidão pela vida conjugal duradoura, bem como a questão religiosa dos votos matrimoniais ${ }^{15,17}$.

Percebe-se a obrigação moral dos filhos em cuidarem de seus pais:

É minha mãe, tanto que ela cuidou de mim, eu falo assim que não faço mais que obrigação de fazer tudo que eu faço por ela. Pra mim é um prazer... (C3)

A obrigação filial é uma norma socialmente construída $^{18}$, aceita sem indagações, considerando a retribuição do cuidado recebido, o respeito mútuo, gratidão, sendo a única opção para os filhos ${ }^{19,20}$.

Diante disso, ao assumir a atividade de cuidado, percebe-se que não se trata de um ato pensado, uma opção, mas sim uma imposição de tarefas veladas já existentes entre os membros de uma família.

A facticidade é muito importante na concepção existencial de Heidegger e é só na facticidade da sociedade, em termos de uma identidade e de um sistema de valores, que se exerce a decisão pessoal a qual se define a existência?.

Diante da facticidade que as fez cuidadoras, percebe-se no conteúdo manifesto de que somente um membro da família assume o cuidado e este não recebe ajuda de outros familiares:

Meus irmãos não me ajudam, nem oferecem ajuda, ninguém se oferece para eu poder sair, vai fazer um ano que estou aqui, ninguém dá uma ajuda, nem nada (C8).

Uma vez que o cuidador assume responsabilidades, cada vez mais a tarefa torna-se intransferível e os outros membros se desvencilham da tarefa. Quando os demais membros da família não se articulam a fim de auxiliar o cuidador principal do idoso, cria-se uma situação de sobrecarga em um só elemento ${ }^{5,21}$. Dessa forma, pode-se inferir o cuidado como a entrega do estar-aí às possibilidades mais próximas.

\section{Ser-cuidador e o abandono de si mesmo e dos outros entes}

No momento que o homem passa a agir de acordo com o que é definido como certo na sociedade, ele experiencia a queda, um verdadeiro estado de decadência, de abandono e desamparo ${ }^{7,8}$. 
O cuidador tem a clara percepção do abandono de si em diversas questões em sua vida particular e social em detrimento do cuidado:

Às vezes a gente tem vontade de sair um pouquinho, viajar... a gente não vai por causa dele, tenho uma filha que mora em outra cidade, eu sempre visitava ela, agora não posso mais ir. (C4).

Tenho vontade de estar no meio das pessoas, tudo junto contando as coisas, conversando, estou sentindo falta mesmo (C5).

$\mathrm{Na}$ impossibilidade do contato com seus próprios filhos e de cultivar as amizades, o viver para cuidar parece gerar um sentimento de insatisfação e desesperança nas cuidadoras, angustiando-as, uma vez que o desejo passa a ser sufocado pelos deveres e obrigações.

O cuidador vê-se diante da impossibilidade de atividades de lazer, já que a tarefa de cuidar é intermitente e não há presença de outras pessoas que realizem tal função enquanto está fora de casa, alterando sua vida social ${ }^{20,22,23}$. Aos poucos, o cuidador percebe-se sozinho, solitariamente na esfera doméstica, com distanciamento dos círculos de amizade ${ }^{24}$, comprometendo o seu bem- estar e saúde mental ${ }^{4}$.

Outra questão enunciada por algumas das cuidadoras, que traz as questões de renúncia, refere-se ao ter que deixar de trabalhar fora de casa:

Sinto, sinto falta de trabalhar... eu gostava de sair de casa, eu não via a hora de ir no serviço, não queria voltar para casa e encarar ele, mas passou... não tem mais jeito de trabalhar agora (C9).

As falas trazem à tona o fato de usarem o recurso da saída para o trabalho como uma forma de alívio no cuidado com o idoso. Quando isso não é mais possível, o cansaço e a desesperança parecem se agravar, uma vez que não podem mais ser aliviados.

trabalho, além de ser importante como recurso orçamentário da família, é tido, também, como uma possibilidade lúdica que auxiliaria a pessoa a se des-ocupar-se do idoso por um período de tempo 5,22 , significando alívio, bem como possibilita o encontro com as questões de ordem pessoal. Entretanto, o abandono da atividade profissional foi a alternativa encontrada pela condição de vida e de doença do ser cuidado. Isso fez com que essas cuidadoras se vissem obrigadas a modificarem seus planos de vida.

Além do abandono de ocupações laborativas, as cuidadoras foram unânimes em considerar o abandono da sua saúde ao assumir a tarefa de cuidar, trazendo relatos de autonegligência, sintomas físicos:

Essa diabetes minha tudo por causa dessa pressão [...] meu médico ficou bravo comigo disse que eu não estou me cuidando direito, não meço minha glicose, não marco a consulta, não vou ao médico na época certa (C4).
Eu fico assim com uma fraqueza, [...] porque me sinto cansada, tem que andar depressa, fazer tudo depressa. [...] Me sinto sobrecarregada, tem dia que é mais suave, tem dia que é muito, muito pesado mesmo (C2).

A autonegligência quanto à própria saúde vista em cuidadores de idosos e a não adesão ao seu próprio cuidado colocam em risco não só a saúde, mas também influencia a qualidade da assistência prestada ao idoso, já que a sua competência para realizar os cuidados pode ser determinada pela capacidade de cuidar de si próprio ${ }^{5,25}$.

Ao desempenhar a tarefa de cuidar do idoso, o relato de cansaço parece estar relacionado à ausência de perspectiva de repouso em curto prazo, o aumento progressivo da dependência do idoso e o acúmulo de papéis do cuidador ${ }^{5,26}$.

O abandono de si leva a cuidadora a um sentimento de anulação da própria vida:

Mudou muitas coisas, meus sonhos, meus ideais, meus objetivos, minhas metas... eu não posso mais pensar nisso. Mas, a gente tem sonhos (C6).

No discurso, percebe-se o paradoxo necessidade e possibilidade. A cuidadora esgota-se perdendo o vínculo com as suas necessidades, vivenciando a angústia que a afasta de si mesma, desrespeitando as suas próprias fronteiras existenciais?

Se olhar para o ser-aí como constituído de pre-ocupação, há o sentido de que o dasein se antecipe à existência do outro; nessa pre-ocupação, acaba por assumir o lugar do outro, mas esquece de si mesmo, ou seja, preocupa-se com o outro e se esquece do verdadeiro sentido de sua própria existência ${ }^{5}$. Essa preocupação não é positiva, uma vez que assume a forma de impessoalidade.

\section{Ser-cuidador lançado no mundo do ser idoso}

Cuidar do idoso com algum tipo de transtorno mental ou comportamental torna-se um desafio à família enquanto evento perturbador e estressante dentro do ciclo de vida familiar. A pessoa que assume a reponsabilidade pelo idoso com Transtorno Mental ou Comportamental parece vivenciar a insegurança e desorientação diante da imprevisibilidade dos comportamentos do idoso:

Ele levantava, estava muito nervoso e agressivo, ficava andando pela casa, a gente levantava correndo, pois tinha que trancar as portas e pegar as chaves. Às vezes saía para a rua, tinha que correr atrás (C2).

A agressividade, o descontrole e a inquietação que o idoso pode apresentar causam um clima de intranquilidade, gerando sentimento de grande aflição no cuidador, o que ocasiona sobrecarga e desgaste físico. Quem cuida precisa, constantemente, estar atento às desorientações, perambulações, reações agressivas, exigindo uma atenção maior e contínua ${ }^{27,28}$.

Os sentimentos de impotência frente ao comportamento do idoso são também elucidados: 
Ele não tem vontade de nada, acabou! Se você der comida, ele come e se você não der, ele não come (C4).

Muitos cuidadores parecem não se conformarem em presenciar o familiar, que poderia desenvolver seus projetos de vida e se integrar socialmente, transformar-se em uma pessoa dependente, desprotegida e tomada por limitações de toda natureza ${ }^{27}$.

O cuidar contínuo do idoso com desordem psiquiátrica possibilita outros sentimentos, como o de raiva, desvelado por essa cuidadora:

Tem dia, que por ele reivindicar muitas as coisas eu sinto assim... raiva! (C1)

O sentimento de raiva pode ser explicado considerando uma possível dificuldade das cuidadoras em entender a doença. A pouca compreensão sobre o transtorno mental e comportamental gera inabilidade diante dos comportamentos e atitudes do idoso ${ }^{28}$.

Outra situação que o sujeito do estudo elucida com tonalidade afetiva refere-se à finitude da vida:

Tenho medo de perdê-lo, porque a gente não quer, eu faço tudo, mas não quero que isso termine, pode durar vinte ou mais trinta anos (C5).

Ao se deparar com a morte do idoso, o cuidador questiona a inexorabilidade de sua própria morte ${ }^{6}$, sua finitude. Um fim que pode ser repentino e, em princípio, parece algo exterior, fora de controle, que inquieta e assusta o homem diante da exterioridade, da imprevisibilidade da morte?

Se o fenômeno do cuidado pode propiciar o ser do dasein ${ }^{7}$, o cuidador, ao desvelar seus sentimentos e ficar de frente com suas angústias e aflições, foi capaz de transcender e atingir um poder-ser-si-próprio, com liberdade de entender seu mundo e si mesmo, sendo capaz de questionar sua própria trajetória de forma genuína.

\section{Ser-com encontra na fé um novo significado para o cuidado}

Se o homem é um ente cujo ser se dá como ser-no-mundo, aspectos fundamentais da existência humana - como suas crenças - interpretam o mundo, a própria história e a si mesmo ${ }^{29}$.

Para as cuidadoras de idosos com transtorno mental e comportamental, a tarefa de cuidar passa a ser uma oportunidade de expressar a sua fé:

Aí, eu entrego nas mãos de Deus, eu sou muito feliz, ele vai é dar muita felicidade, muita paz, eu vou morrer tranquila, pelo menos pude cuidar da minha mãe, fiz a minha parte (C8).

Percebe-se que, ao assumirem o cuidado, interpretado como sendo algo capaz de propiciar o contato com o sagrado, as cuidadoras encontram um mecanismo de enfrentamento dessa situação. $\mathrm{O}$ cuidar pode ser um mecanismo de sublimação, ao exaltar e tornar subli- me o cuidado por meio da fé. Desse modo, a religião possibilita dar um novo sentido e significado ao que é vivenciado ${ }^{30,31}$, encontrando segurança e conforto para desenvolver a tarefa. Também, o cuidador, com suas convicções religiosas e espirituais, parece aceitar melhor e sentir-se apoiado, contribuindo para a diminuição de conflitos internos e da sobrecarga frente aos desafios da ocupação ${ }^{32,33}$.

Na decadência e imerso na vida inautêntica é que o homem busca seu verdadeiro caminho. Abre-se em busca de possibilidades para a existência. Apegando-se a suas crenças, recria a si mesmo e a suas práticas. $\mathrm{O}$ cuidado pode tornar-se um espaço potencial para o amadurecimento e desenvolvimento da autenticidade do ser?

\section{ConClusão}

O estudo possibilitou uma abordagem ao ser cuidador em uma perspectiva ontológica, indo além, alcançando a essência e o sentido do ser. Assim, o cuidador é olhado em sua existência e entendido em seus sentimentos, vivências e significados, compreendido não como mero cuidador, mas um ser humano que se sente sobrecarregado e esquecido, que espera ser ouvido, visto e cuidado.

Portanto, sugere-se que sejam público-alvo de atenção nas unidades de ESF, garantindo a eles um espaço de apoio à saúde física e emocional e de desenvolvimento de habilidades em lidar com as doenças mentais e comportamentais do idoso. Recomenda-se que, ao se trabalhar com cuidadores informais de idoso, devam ser considerados aspectos culturais, o papel do feminino na história do cuidado, assim como as relações familiares e os sistemas de valores sociais, para, assim, estabelecer estratégias de cuidado com o cuidador informal segundo suas vivências.

Entre as limitações da pesquisa, os resultados são apresentados pela experiência e intencionalidade dos sujeitos frente ao fenômeno do cuidado, uma vez que o sujeito é quem descreve o objeto e as suas relações a partir de seu ponto de vista. Portanto, o objeto torna-se um elemento específico, fazendo com que os resultados descritos sejam característicos desta população estudada. Por outro lado, as concepções e interpretações do fenômeno também incorrem na intencionalidade do pesquisador. No entanto, a importância deste estudo está alojada neste mesmo contexto, ou seja, é a experiência do sujeito no cuidado de idosos que possibilita aproximar de uma compreensão do fenômeno de ser cuidador.

\section{REFERÊNCIAS}

1.Organização Mundial da Saúde. Relatório Mundial de Envelhecimento e Saúde. Genebra (SWI):OMS; 2015. 2.Clemente AS, Loyola AI, Firmo JOA. Concepções sobre transtornos mentais e seu tratamento entre idosos atendi- 
dos em um serviço público de saúde mental. Cad Saude Publica.2011; 27:555-64.

3.Maia LC, Durante AMC, Ramos LR. Prevalência de transtornos mentais em área urbana no norte de Minas Gerais. Rev Saúde Publica. 2004; 38:650-56.

4.Nascimento LC, Moraes ER, Silva JC, Veloso LC, Vale ARMC. Cuidador de idosos: conhecimento disponível na base de dados LILACS. Rev Bras Enferm. 2008;61:514-17.

5.Fernandes MGM, Garcia TR. Atributos da tensão do cuidador familiar de idoso dependente. Rev esc enferm USP. 2009; 43:818-24.

6.Pimenta GMF, Costa MASMC, Gonçalves LHT, Alvarez AM . Perfil do familiar cuidador de idoso fragilizado em convívio doméstico da grande região de Porto, Portugal. Rev esc enferm USP. 2009; 43:609-14.

7.Heidegger M. Ser e tempo. 12ª ed. São Paulo: Vozes; 2009. 8.Penha J. O que é o existencialismo? $12^{\mathrm{a}}$ ed. São Paulo: Brasiliense; 2004.

9.Morais SCRV, Monteiro CFS, Rocha SS. O cuidado de enfermagem à mulher vitima de violência sexual. Rev Texto Contexto Enferm.2010; 19:155-60.

10.Oliveira MFV, Carraro TE. Cuidado em Heidegger: uma possibilidade ontológica para a enfermagem. Rev Bras Enferm. 2010; 64:376-80.

11.Husserl E. Ideias para uma fenomenologia pura e para uma filosofia fenomenológica. Aparecida, (SP): Ideias e Letras; 2006.

12.Broomé RE. The selected works of Rodger E [site da Internet]. Descriptive phenomenological psychological method: an example of a methodology section from doctoral dissertation [citado em 25 jul 2015] Disponível em: http://works.bepress.com/cgi/viewcontent. cgi article $=1017 \&$ context $=$ rodger_broome

13.Moreira, DA. O método fenomenológico na pesquisa. São Paulo: Pioneira Thomson; 2002.

14.Campos EL, Cruz S, Mattos ED. Perfil de cuidadores familiares de idosos no Município de Jataizinho PR.UNOPAR Cient Ciênc Biol. Saúde 2010;12(3):57-66. 15.Gonçalves LHK, Costa MAM, Martins MM, Nassar SM, Zunino R. Dinâmica da família de idosos mais idosos no contexto de Porto, Portugal. Rev Lat- Am Enfermagem. 2011; 19:9.

16.Santos AA, Pavarini SCI. Perfil dos cuidadores de idosos com alterações cognitivas em diferentes contextos de vulnerabilidade social. Rev Gaucha Enferm. [Scielo-Scientific Eletronic Library Online] 2010 [citado em 10 jul 2015]. 31(1)115-22. Disponível em: http://www.scielo.br/scielo. php?pid=S1983-14472010000100016\&script $=$ sci_arttext 17.Braz E, Ciosak SI. O tornar-se cuidadora na senescência. Esc Anna Nery. 2009; 13:372-7.

18.Falcão DVS, Bucher-Maluscke JSNF. Cuidar de familiares idosos com a doença de Alzheimer: uma reflexão sobre aspectos psicossociais. Psicol Estud. 2009; 14:777-86.

19.Flores GC, Borges ZN, Budó MLD, Mattioni FC. Cuidado intergeracional com o idoso: autonomia do idoso e presença do cuidador. Rev Gaucha Enferm [Scielo-Scientific
Eletronic Library Online] 2010 [citado em 10 jul 2015]. 31:467-74. Disponível em http://www.scielo.br/scielo. php? script =sci_arttext\&pid=S1983-14472010000300009. 20.Oliveira APP, Caldana RHL. As repercussões do cuidado na vida do cuidador familiar do idoso com Demência de Alzheimer. Saúde soc. [Scielo-Scientific Eletronic Library Online] 2012 [citado em 02 jun 2014]. 21:675-85. Disponível em: http://www.scielo.br/scielo.php?pid=S0104$12902012000300013 \&$ script $=$ sci_arttext

21.Cruz DCM, Loureiro HAM, Silva MANCGMM, Fernandes MM. As vivências do cuidador informal do idoso dependente. Referência. 2010; 3(2):127-36.

22.Fonseca NR, Penna AFG, Soares MPG. Ser cuidador familiar: um estudo sobre as consequências de assumir este papel. Physis (Rio de Janeiro). 2008;18:727-43.

23.Pinto MF, Barbosa DA, Ferreti CEL, Souza LF, Fram DS, Belasco AGS. Qualidade de vida de cuidadores de idosos com doença de Alzheimer. Acta Paul Enferm. 2009; 22:652-57.

24.Brito ES, Rabinovich EP. A família também adoece! Mudanças secundárias a ocorrência de um acidente vascular encefálico na família. Interface comum saúde educ. 2008; 12 (27):783-94.

25.Clock D, Godoy GM, Petry G, Capistrano JW, Spena RJ. Quem cuida do cuidador. Caderno de Publicações Acadêmicas [periódico na Internet]. 2009 [citado em 20 jun 2015]; 1(1): [aproximadamente 4p.]. Disponível em: https://periodicos.ifsc.edu.br/index.php/publicacoes/article/ view/79/43

26.Minayo MCS. Antropologia, saúde e envelhecimento. Rio de Janeiro: FIOCRUZ; 2002.

27.Sant'Ana MM, Pereira VP, Borenstein MS, Silva AL. O significado de ser familiar cuidador do portador de transtorno mental. Rev Texto Contexto Enferm. 2011; 20:50-8. 28.Avelino ACA, Cunha AAR, Silva PMCS, Azevedo EB, Silva JB,Ferreira Filha MO. O cuidado ao idoso portador de transtorno mental sob a ótica da família. Referência. 2013; 3(8):75-83.

29.Sales CA. O ser-no-mundo e o cuidado humano: concepções Heideggerianas. Rev enf UERJ. 2008; 16:563-8.

30.Silveira TM, Caldas CP, Carneiro TF. Cuidando de idosos altamente dependentes na comunidade: um estudo sobre cuidadores familiares principais. Cad Saude Publica. 2006; 22:1629-39.

31.Cartaxo H. G. O. Vivência dos cuidadores familiares de idosos dependentes: revelando estratégias para o enfrentamento do cotidiano. Estud Interdiscip Envelhec. 2012; 17(1):59-74.

32.Brondani CM, Beuter M, Alvim NAT, Szareski C, Rocha LS. Cuidadores e estratégias no cuidado ao doente na internação domiciliar. Rev Texto Contexto Enferm [Scielo-Scientific Eletronic Library Online] 2010 [citado em 02 jun 2015]. 19:504-10. Disponível em: http://www. scielo.br/pdf/tce/v19n3/a12v19n3.pdf.

33. Marques AKMC, Landim FLP, Collares PM, Mesquita RB. Apoio social na experiência do familiar cuidador. Ciênc Saúde Coletiva. 2011;16 supl 1:S945-55. 